\title{
DESIGN OF DETECTING ACOUSTIC WAVES AT THE EXERCISE SMART MINE USING ACOUSTIC SENSOR
}

\author{
I Nengah Putra $\mathrm{A}^{1}$, Nuri Nur Cahyono ${ }^{2}$, Gesit Pratiknyo ${ }^{3}$, M Sigit Purwanto ${ }^{4}$ \\ ${ }^{1}$ Indonesia Defense University, UNHAN Jakarta Indonesia \\ 2,3,4 Indonesian Naval Technology College, STTAL Surabayalndonesia
}

\begin{abstract}
The Indonesian Navy is a unit of defense of the Republic of Indonesia (NKRI). Sea mines are explosive devices placed in waters to destroy ships. Acoustics is a branch of physics that deals with all mechanical waves in liquids, gases and solids, such as vibration, sound and ultrasonic. Arduino has made microcontroller technology more accessible and easier for even novice users. Because of this, there are special functions in audio or acoustic processing techniques aimed at using Arduino. The application of acoustic signals in the military field of the Navy, in the identification of vessels caught by the microphone receiver. The movement of objects that are caught by the microphone will be analyzed to conclude the object. From the results of the sound characteristics raised by the object, it will give a different picture for different variations of the object. Processing acoustic signals using DSP will make it easier to infer the captured acoustic signal. The circuit board used is a microphone signal amplifier and signal conditioner, for processing the audio signal obtained from the microphone and to produce output data which is the result of the process using Arduino. Analog-to-digital converter $(A D C)$ of the microcontroller works in the voltage range from $0.0 \mathrm{~V}$ to $+3.3 \mathrm{~V}$ or $+5.0 \mathrm{~V}$. To achieve good sampling results, that the signal peak is close to the maximum value of the ADC. Additionally, voltage amplitudes above this threshold can damage the controller input port or produce unwanted harmonics. Therefore, a signal pre-amp circuit is needed to guarantee the appropriate audio sample signal as well as to protect the system. The test results obtained from the system analyzer frequency and signal meters can be used to identify acoustic signals.
\end{abstract}

Keyword: Singnal Acoustic/michophone, controller, Arduino Uno, pre-amp frequency analyzer

\section{INTRODUCTION}

TNI AL is a defense and resilience unit of the Republic of Indonesia (NKRI). In carrying out defense and endurance missions, the NAVY required a managed and monitored security support system. The security management system applied to the TNI AL environment must have high enough security standards, this is to support the safety and security quality of internal and external breaches. One of the points of the NAVY support system is the security system at the entrance of care. As the main entrance, the armed forces system of the Navy involved the guard personnel and security support system in monitoring, so that it becomes an early identification way for the parties who want to do a breach.

Sea mines are explosive devices in the waters to blow up vessels or submarines. Mines are placed in water depths and can explode when enemy vessels are approaching. Mines work if there are target enemy ships approaching mine site, this will activate or trigger mines to explode. Acoustics are physical sciences related to waves in liquids, gases and solids, such Acoustics are physical sciences related to waves in liquids, gases and solids, such as ultrasonik. Acoustics have been applied in almost all aspects of society, such as the example is the application of audio technology. The acoustic term in the sound can be given as a sound wave produced as a background. Acoustic guitars can produce sounds due to the vibration of the guitar body and the consequences of changing air pressure in them. The acoustic Drum struck can result in a sound vibration in the same way as the guitar. The same is the case with acoustic pianos with hammer (hammer) hitting the strings, the violin that swipes, and so forth. The sound can be generated without the electricity involved, the sound spreads through the air media.

Microprocessors, DSP chips, are essential tools embedded in real-time acoustic and audio signal processing. This Chip provides the ability to perform mathematical operations on the input signal. In addition, it can be used to produce the desired output signal. Lately, Arduino has made technology 
about microcontrollers more accessible and easier for novice users. Therefore, there is a special function in audio or acoustic processing techniques aimed at using the Arduino. The application of acoustic signals in the military field of the Navy, on the identification of vessels caught microphone receivers. The movement of objects that caught the microphone will be done analysis process to conclude the object.

From the carateristic result of the raised sound of an object, it will give a different picture to different object variations. Acoustic signal processing using DSP will make it easier to conclude captured acoustic signals. From the results of the captured acoustic signal can trigger the sea mines to explode. For this reason, so that in this research the author will make a design build acoustic signal processing using the Arduino microcontroller. The circuit board used is a microphone signal amplifier and signal-sensing, for processing the audio signal is obtained from the microphone and to produce output data that is the process result using the Arduino. In realizing the acoustic signal processing system to trigger a exploding mine, the author attempts to lift it into a research theme with the research title of The Design of Detecting Acousticwaves at The Exercise Smart Mine using Acoustic Sensor.

In this research need to be formulated problems in the Design of Detecting Acousticwaves at The Exercise Smart Mine using Acoustic Sensor.. Some of these problems are:

a. How to ship identification based on acoustic signals?

b. How the frequency and acoustic signal strength measurements posed by the vessel?

The benefits of The Design of Detecting Acousticwaves at The Exercise Smart Mine using Acoustic Sensor are:

a. As the application of enemy vessel identification system entering the territorial waters NKRI.

b. To trigger mines exploding based on acoustic signals received according to the acoustic signal characteristics of the enemy ships.

\section{RESEARCH METHODS}

\subsection{Types of Research}

Type of research build is The Design of Detecting Acousticwaves at The Exercise Smart Mine using Acoustic Sensor consisting of several steps in the design that contributes to the realization of a Capable device to obtain acoustic signal measurements using Arduino Uno through the dynamic microphone.

\subsection{Research procedure}

To implement well-researched, the preparation of steps to find the data source as well as conducting research of the acoustic wave detection device design in Exercise Smart Mine using acoustic sensors.

\subsubsection{Time and place}

Research conducted by the author is at the campus STTAL Moro Krembangan Surabaya. This study began in July 2019 until the end of December 2019.

\subsubsection{Tools and Materials}

Tools and materials to support this process of research and application of systems.

a. Hardware

Computer or laptop, 4 GB Random Access Memmory RAM, operating system windows 7 .

b. Software

Arduino IDE 1.8.0 Here's the Arduino IDE data that needs to be known before the microcontroller program creation process, the Arduino IDE Studio is available on the Windows, Linux and MAC versions of minimum needs system to run the Arduino IDE program, the Arduino IDE Used version 1.8.0. Block Diagram.

\subsubsection{Research draft}

Research draft Arduino-based acoustic system design implements the research stages, as follows:

a. Preliminary studies

Preliminary study is a process of study to obtain information about the research that will be conducted.

b. Problem analysis

Problem analysis is a study to develop problems, as well as solutions and troubleshooting alternatives.

c. Need analysis

Analyst needs require to menyempurnaan existing needs.

d. Design analysis

It is a process of selecting tools to analyze the data, so that the problems can be solved and objectives can be proved. On this hold the author should choose a data analysis tool that corresponds to the data to be acquired on the study in the field. At this step the author can determine which tools can help to determine the design of data communication and the objectives can be realized. 


\section{e. Design}

Based on the study of the draft analysis in advance, information can be obtained to make the process of designing the acoustic system.

\subsubsection{Data Collection}

At the design of the wave detection system in Exercise Smart Mine research using acoustic sensors The author conducts the study with data collection. The method of research data collection design the Arduinobased acoustic system that the author will do, namely:

a. Interviews, is a question and answer to the competent party about the communication of data wirelessly.

b. Observation, is a direct research in the field.

c. Documentation, is a way of collecting data from books, records, and research outcomes in related agencies on acoustic systems.

\subsubsection{Data processing}

Data processing is a process by which authors have taken some information collected in the data collection process. The Data obtained will be conducted and become reference to the design and system design analysis process.

\section{DESIGNING, IMPLEMENTING AND TESTING SYSTEMS}

In this planning chapter, implementation, and testing, discusses the acoustic design of acoustics as the acoustic signal identification device produced due to the sound of vessels that are approaching mine site. The acoustic signal identified in the design of the acoustic system is the signal strength and the measurement sound meter is carried out using an analog mic which is integrated with the power of the device, via analog pin.

\subsection{System Design}

In designing the system need to be analyzed in advance about the signal condition circuit that can be explained the concept of work. The analog-to-digital converter (ADC) of the microcontroller usually works on a voltage range from $0.0 \mathrm{~V}$ to $+3.3 \mathrm{~V}$ or $+5.0 \mathrm{~V}$. To achieve a good sampling result, that signal peaks are close to the maximum value of ADC. In addition, the voltage amplitude above this threshold can damage the controller's input port and/or generate unwanted harmonics. Therefore, a signal customizer circuit is required to guarantee a signal- appropriate audio sample as well as to protect the system. If desired to connect the microphone output to the board, a pre-amp set should be applied. The circuit design depends heavily on microphone characteristics.

Using the op-amp AD8606 can be used at an equivalent source of an Arduino board. Most of the OP-amps cannot achieve the voltage output as high as the power supply. Maximum can reach generally $3 / 4$ volts under the source of voltage, which is a problem when trying to build a system that works on lowvoltage batteries. Because of this problem, an opamp rail-to-rail is selected, which can be reached at the full voltage range of the supply. Another advantage Opamp AD8606 is a single-source operation, to avoid the need for symmetrical power supply.

The range is simulated from $20 \mathrm{~Hz}$ to 20 $\mathrm{KHz}$ in software series modeling and simulation. For the Electret microphone, a preamp circuit based on an operational amplifier (or OPAMP) is designed, as shown in Figure 3.1.

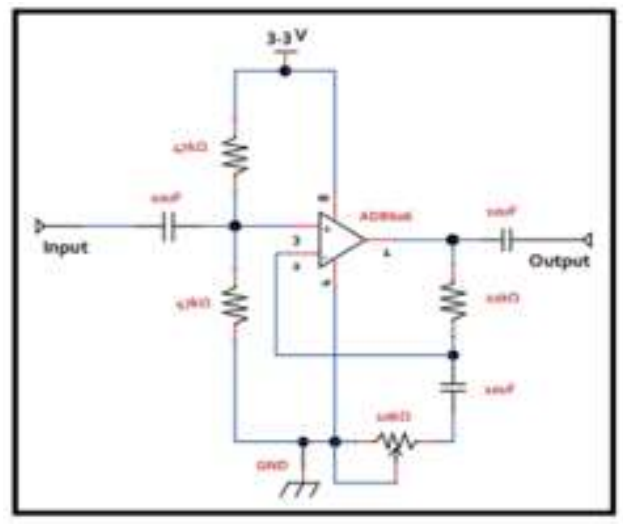

Figure 3.1 The signal-sensing Pre-AMP series

Before antialiasing filter should be designed according to system objectives and the relative frequency range needed. Without this filter between (or before) amplifier and analog inputs, unstable systems (spectral folding effects or aliasing effects). There are several low-pass integrated circuits, such as the MAX 291/292/295/296, this filter can be easily used as an anti-aliasing filter.

To explain the system work process in a gloom, the flow diagram of the system work process is created. The working system starts from the acoustic signal pickup using the microphone, reinforcing the signal from the still weak microphone using. Pre-Amp.

Conditioned analog signal to the level of the ADC Arduino's voltage range. At the author's design determine the point 0 signal on the 0.5 maximum level of ADC Arduino. It is known that the maximum level of the ADC 
Arduino is $5 \mathrm{VDC}$ so that the 0 point signal resides on the 2.5 VDC ADC Arduino.



Figure 3.2 Block Diagram System

To explain the overall process, the flow diagram of the system work process is created. The work system starts from Picup the acoustic signal using the microphone, reinforcing the signal from the still weak microphone using pre-amp and constrain the analog signal to the level of the voltage range of the ADC Arduino. At the author's design determine the point 0 signal on the 0.5 maximum level of ADC Arduino. It is known that the maximum level of the ADC Arduino is $5 \mathrm{VDC}$ so that the 0 point signal is at $2.5 \mathrm{VDC}$ ADC Arduino.

In designing the system need to be analyzed in advance about the signal condition circuit that can be explained the concept of work. The analog-to-digital converter (ADC) of the microcontroller usually works on a voltage range from $0.0 \mathrm{~V}$ to $+3.3 \mathrm{~V}$ or $+5.0 \mathrm{~V}$. To achieve a good sampling result, that the signal peaks are close to the maximum value of ADC.

In addition, the voltage amplitude above this threshold can damage the controller's input port and/or produce unwanted harmonics. Therefore, a signal customizer circuit is required to guarantee a signalappropriate audio sample as well as to protect the system. If desired to connect the microphone output to the board, a pre-amp set should be applied. The circuit design depends heavily on microphone characteristics.

Figure 3.3 The following describes the work process of the device in the System flowchart form.

\subsection{Software and Hardware Analysis}

For the implementation of acoustic system, some things that need to be done are as follows.

a. Pre-AMP is a circuit of signal conditioning and signal amplifier. Since the Arduino can only process a digital signal it is necessary to do the process to convert analog to digital via an analog to digital converter. The analog-to-digital converter (ADC) of the microcontroller working at voltages $+3.3 \mathrm{~V}$ to $+5.0 \mathrm{~V}$. To achieve the sampling result of the microphone device, the peak signal must not exceed the maximum value of ADC. To receive coordinate data from the author's Client transceiver using the LoRa Shield v95 $915 \mathrm{MHz}$ hardware as side of the Gateway transceiver. This Shield uses techniques

b. Retrieval of data sampling in the form of signal strength $(\mathrm{dB})$ and sampling of frequency retrievals as much as 256 data per second. It aims to determine the frequency of the response to the captured signal. In this case, the sound of the ship.

\subsection{Data Needs Analysis}

Testing of this research was implemented to obtain the expected data. Some of them are testing reception of acoustic signal frequencies and acoustic signal strength displayed through the PC monitor screen.

\subsubsection{Testing Microphone Module Max4466}

To test the MAX4466 microphone module set, the things that need to be done are wiring or cabling modules with Arduino Uno devices. Wiring diagram circuit shown as Figure 3.4 follows. In the 3.4 figure the power supply microphone module is associated with the Arduino power supply source, and the module output is connected to the analog in A1 Arduino. MAX4466 module can operate from voltage $+2.4 \mathrm{~V}$ to $+5.5 \mathrm{~V}$ power supply.



Figure 3 .4 Microphone circuit wiring test 




Figure 3.5 Pre-amp Microphone MAX4466

At the acoustic signal processing test, the authors test in two modes, the first mode of testing against frequency response in time domain using Fast Hartley Transform (FHT) and signal strength in decibels $(\mathrm{dB})$. One way to process acoustic data, Mainly related problem solving and development in visualizing acoustic signal analysis, namely using FHT Program library that can be applied in Arduino programming, run FHT data and send it in binary form through serial data to PC or laptop device. The following figure 4.5 is the result of the frequency response test displayed on the $\mathrm{C \#}$ program interface. In the results of the test image 3.6 The authors do not inject the signal using a frequency generator to the microphone but let the room noise level as the initial testing.



Figure 3.6 Images test result frequency response at room frequency

On testing to two authors using the frequency of generators that run on an Android device. Frequency generator applications can generate frequencies that are generated on the device speaker used as a frequency source. These tests are divided into several tests starting with $500 \mathrm{~Hz}, 1000 \mathrm{~Hz}, 1500 \mathrm{~Hz}$, $2000 \mathrm{~Hz}, 2500 \mathrm{~Hz}, 3000 \mathrm{~Hz}, 3500 \mathrm{~Hz}, 4000 \mathrm{~Hz}$, $4500 \mathrm{~Hz}$ and $5000 \mathrm{~Hz}$ frequencies. Test results will be presented in the frequency response graph relating to the frequency of the domain Identified. The following images of response frequency test results in each response frequency test.



Figure 3.7 Images test Results $500 \mathrm{~Hz}$ response



Figure 3.8 Images test Résultat $1000 \mathrm{~Hz}$ réponse

The Arduino program code that runs the frequency spectrum process can be seen in the following program code. The program code explains the sampling process of data through analog A0 pins as much as 256 sampling. Retrievals the 256 sampling value in 1 -second intervals. So that every 1 second will be conducted a frequency spectrum data plot on a graphical program interface. 



The C\# program code on the plot process graphs the frequency spectrum, viewable in the following code snippet.



On testing to three authors using a frequency generator that runs on Android device to evoke $1000 \mathrm{~Hz}$ frequency with personalised volume level to get signal strength level. This test is done to get information about the system that is created to detect signal strength through the microphone in a dB unit..



Figure 3.9 Images signal strength test result$10 \mathrm{~dB}$ at $1000 \mathrm{~Hz}$ frequency



Figure 3.10 Images of signal strength test result-9dB at $1000 \mathrm{~Hz}$ frequency



Figure 3.11 Images signal strength test result$8 \mathrm{~dB}$ at $1000 \mathrm{~Hz}$ frequency



Figure 3.12 Image signal strength test result$6 \mathrm{~dB}$ at $1000 \mathrm{~Hz}$ frequency 




Figure 3.13 Images of signal strength test results- $5 \mathrm{~dB}$ at $1000 \mathrm{~Hz}$ frequency



Figure 3.14 Images signal strength test result$4 \mathrm{~dB}$ at $1000 \mathrm{~Hz}$ frequency

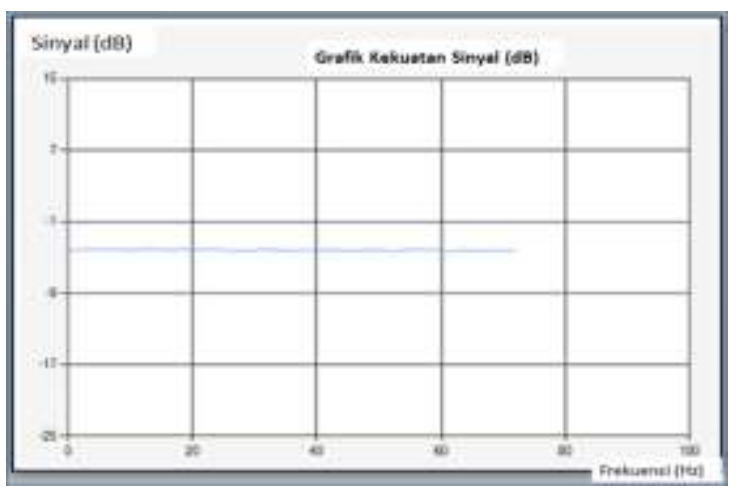

Figure 3.15 Image signal strength test result$3 \mathrm{~dB}$ at $1000 \mathrm{~Hz}$ frequency

In testing the four authors use a frequency generator that runs on the Android device to generate a frequency of $2000 \mathrm{~Hz}$ with a modified volume level to get the signal strength level. This test aims to obtain information about whether the system created can detect signal strength through the microphone in a $\mathrm{dB}$ unit.



Figure 3.16 Image signal strength test result$10 \mathrm{~dB}$ at $2000 \mathrm{~Hz}$ frequency

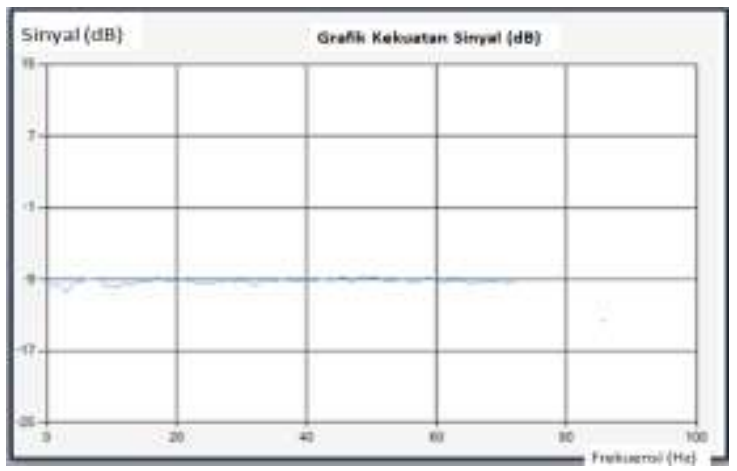

Figure 3.17 Images of signal strength test result-9dB at $2000 \mathrm{~Hz}$ frequency



Figure 3.18 Images of signal strength test result- $8 \mathrm{~dB}$ at $2000 \mathrm{~Hz}$ frequency

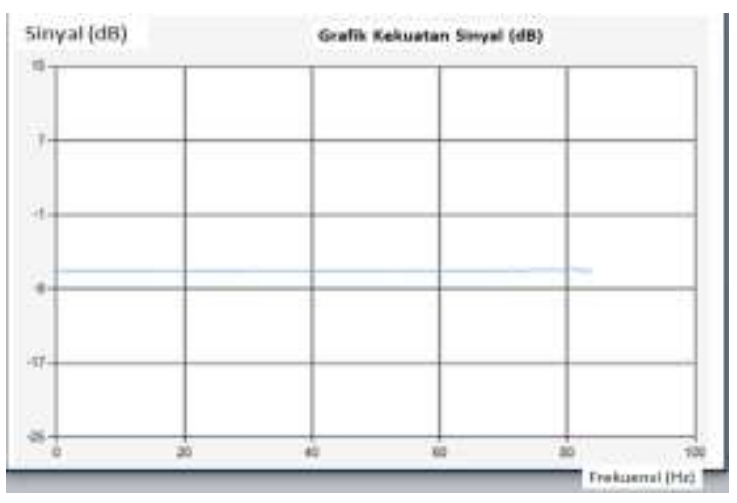

Figure 3,19 Images of signal strength test result- $7 \mathrm{~dB}$ at $2000 \mathrm{~Hz}$ frequency 


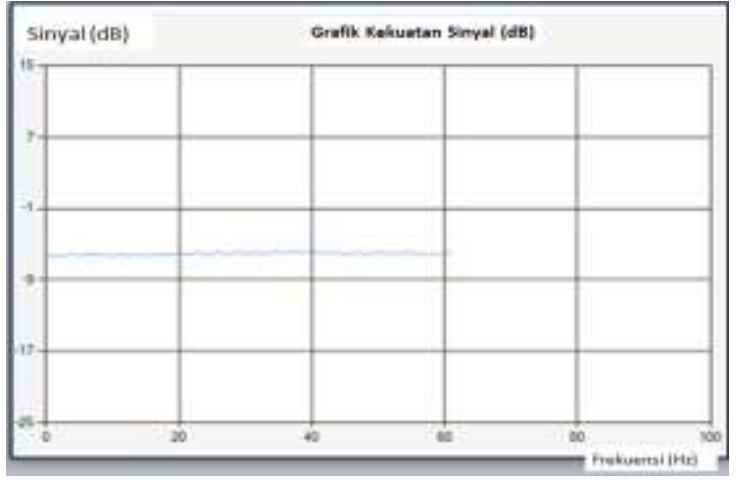

Figure 3.20 Image signal strength test result$6 \mathrm{~dB}$ at $2000 \mathrm{~Hz}$ frequency

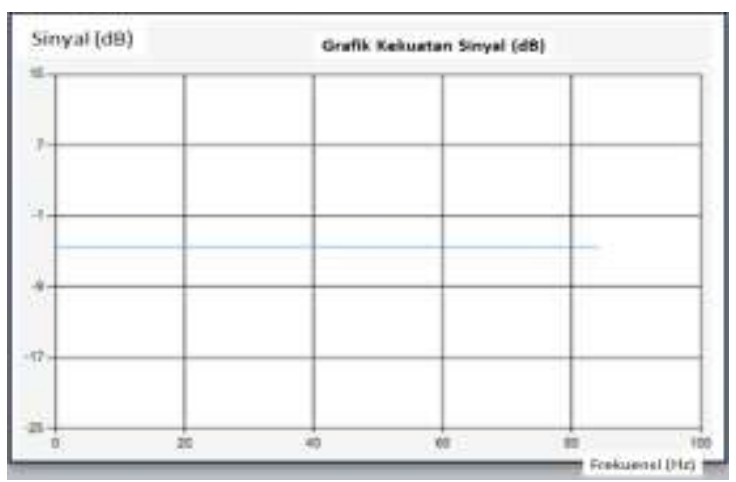

Figure 3.21 Image signal strength test result$5 \mathrm{~dB}$ at $2000 \mathrm{~Hz}$ frequency



Figure 3.22 Image signal strength test result$4 \mathrm{~dB}$ at $2000 \mathrm{~Hz}$ frequency



Figure 323 Image Signal strength test result$3 \mathrm{~dB}$ at $2000 \mathrm{~Hz}$ frequency
In this test the maximum level of readable signal is $-3 \mathrm{~dB}$, raising the signal level on the generator does not change the reading level of the device.

From signal strength testing, you can test the Arduino program code in volume measurements in a dB unit. The following Arduino program codes acoustic Signal processing.



Meanwhile for the program code plot strength signal in the form of graphs can be seen on the code snippet following $\mathrm{C \#}$ program.

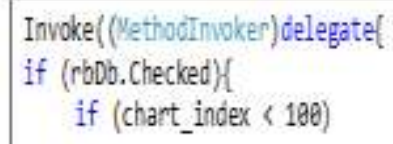

\section{CONCLUSIONS}

Conclusions that can be mentioned as follows:

a. The identification of vessels based on the signal can be carried out in accordance with the charateristic vessel frequency, whereby each vessel has a characteristics of acoustic signals with the dominant frequency at a certain value. The test results obtained by the system ability to filter at a specific frequency according to the vessel frequency characteristics of $1000 \mathrm{~Hz}$ and $2000 \mathrm{~Hz}$.

b. Based on the results of the test frequency measurement and acoustic signal strength, proved that the system has the ability to acquire data on the acoustic signal spectrum at $20 \mathrm{~Hz}-20000 \mathrm{~Hz}$ frequency range. 
c. Developed a wave detection system in Exercise Smart mine that can identify or identify vessels based on acoustic signals using artificial intelligence.

d. Improve microcontroller capability by replacing to ARM-Cortex microcontroller which has more signal processing capability, on the other hand of ARM-Cortex has built-in microphone and audio amplifier.

\section{ACKNOWLEDGEMENT}

The authors greatly acknowledge the support from STTAL Surabaya and UNHAN Jakarta Indonesia for providing the necessary resources to carry out this research work. The authors are also grateful to the anonymous reviewers and journal editorial board for their many insightful comments, which have significantly improved this article.

\section{REFERENCE}

Andrianto, Heri and Aan Darmawan. 2016. Arduino Quickly Learning and Programming. Bandung : Informatika Bandung. B. Gustomo. 2015.

Arduino, 2016, Arduino Uno Board, https://www.arduino.cc/en/Main/Arduino BoardUno, June 11 2019.

Kadir, Abdul. A Practical Guide Learning Microcontroller Applications and Programming Using Arduino. Yogyakarta : C.V Andi Muis, Saludin. 2013

Malwan, Paulus Andi, Practical Guide to AT89C51 Microcontroller Interface and Programming, PT. Elex Media Komputindo, Jakarta, 2003.

Malwan, Paulus Andi, Practical Guide to Using and Interface the M1632 LCD Module, PT. Elex Media Komputindo, Jakarta, 2004.

Ramadhan, M. Fajar. 2016 , Audio Output on Wireless Connected Speakers using Microcontroller Based Android. Palembang, State Polytechnic of Sriwijaya.

Silaen P, Maryxon.2018. Design of Visual Glasses and GPS Compass Visual Appearance Using a Microcontroller for the Marine. Surabaya.

www.arduino.cc/en/Products/Counterfeit. July $2^{\text {th }} 2019$.

Zamzabil, Ginda Okfriano. 2015. Bluetooth Speaker Based on Atmega 8535
Microcontroller. Palembang, State Polytechnic of Sriwijaya. 